\title{
Faculty Perceptions of Challenges to Educating Engineering and Computing Students About Ethics and Societal Impacts
}

\section{Ms. Madeline Polmear, University of Colorado, Boulder}

Madeline Polmear is a PhD student in the Department of Civil, Environmental, and Architectural Engineering at the University of Colorado, Boulder. Her research interests include ethics education and societal impacts of engineering and technology.

\section{Dr. Angela R. Bielefeldt, University of Colorado, Boulder}

Angela Bielefeldt is a professor at the University of Colorado Boulder in the Department of Civil, Environmental, and Architectural Engineering (CEAE). She has served as the Associate Chair for Undergraduate Education in the CEAE Department, as well as the ABET assessment coordinator. Professor Bielefeldt was also the faculty director of the Sustainable By Design Residential Academic Program, a livinglearning community where interdisciplinary students learn about and practice sustainability. Bielefeldt is also a licensed P.E. Professor Bielefeldt's research interests in engineering education include servicelearning, sustainable engineering, social responsibility, ethics, and diversity.

\section{Dr. Daniel Knight, University of Colorado, Boulder}

Daniel W. Knight is the Program Assessment and Research Associate at Design Center (DC) Colorado in CU's Department of Mechanical Engineering at the College of Engineering and Applied Science. He holds a B.A. in psychology from Louisiana State University, an M.S. degree in industrial/organizational psychology and a Ph.D. degree in education, both from the University of Tennessee. Dr. Knight's research interests are in the areas of retention, program evaluation and teamwork practices in engineering education. His current duties include assessment, team development and education research for DC Colorado's hands-on initiatives.

\section{Dr. Chris Swan, Tufts University}

Chris Swan is an associate professor in the Civil and Environmental Engineering department at Tufts University. He has additional appointments in the Jonathan M. Tisch College of Civic Life and the Center for Engineering Education and Outreach at Tufts. His current engineering education research interests focus on community engagement, service-based projects and examining whether an entrepreneurial mindset can be used to further engineering education innovations. He also does research on the development of reuse strategies for waste materials.

\section{Dr. Nathan E. Canney, CYS Structural Engineers Inc.}

Dr. Canney conducts research focused on engineering education, specifically the development of social responsibility in engineering students. Other areas of interest include ethics, service learning, and sustainability education. Dr. Canney received bachelors degrees in Civil Engineering and Mathematics from Seattle University, a masters in Civil Engineering from Stanford University with an emphasis on structural engineering, and a PhD in Civil Engineering from the University of Colorado Boulder. Dr. Canney taught in the Civil and Environmental Engineering Department at Seattle University for four years and now works in private consulting. 


\title{
Faculty Perceptions of Challenges to Educating Engineering and Computing Students About Ethics and Societal Impacts
}

\begin{abstract}
Evaluating ethics and societal impacts (ESI) is an integral part of engineering in an increasingly globalized and technology dependent world. Despite the recognized importance of ESI in engineering education and its inclusion in accreditation criteria, students' instruction on this topic has been widely viewed as deficient. This paper explores some of the challenges that confront educators who teach engineering and computing students about ESI. Between September 2016 and April 2017, 37 interviews were completed via Skype or phone and lasted 30-70 minutes. The interviews were conducted to gain insight into educators' teaching practices and broader perspectives on ESI education. The participants were asked, "what challenges have you encountered in incorporating these topics?" and discussions of challenges also arose spontaneously throughout the semi-structured interviews. Content logs and transcripts of the interviews were created and analyzed using emergent, thematic coding to identify the challenges that faculty experienced in teaching engineering and computing students about ESI. Of the 37 interviews, 31 discussed challenges (or lack there of) and were able to be transcribed; this sub-set is the focus of the paper. Analysis of the data indicated that barriers to effective instruction fell under five broad themes: students, faculty, institutional, curriculum, and engineering skills. Of the interviewees, $23 \%$ encountered only challenges, $64 \%$ described both challenges and affordances, and 13\% described not encountering any challenges. Despite the obstacles, the interviewees expressed the importance of integrating ESI into engineering education and produced examples of teaching these topics in a range of settings with a variety of pedagogical approaches. Analysis of the interview data from educators who did not perceive any significant challenges also sheds light on the circumstances and strategies that facilitate effective ESI instruction.
\end{abstract}

\section{Introduction}

Ethics has been recognized as an important part of engineering education and professional responsibility. The inclusion in accreditation criteria [1] and professional codes [2] provides an impetus for fostering ethical awareness and judgment. In a systematic literature review of engineering ethics education articles, Hess and Fore found that $65 \%$ of the interventions were justified or motivated by ABET accreditation [3]. Despite its importance, there are a number of "systemic barriers to effective ethics education" [4, p. 346]. One challenge is a lack of student engagement, which can be evidenced on course evaluations where "students overwhelmingly rate the ethics component of the course as the least interesting, least useful, and the most trivial" [4, p. 347]. This aligns with Cech's examination of the culture of disengagement within engineering [5]. In a longitudinal study of 326 engineering students, Cech found students' commitment to public welfare, as measured by the importance they place on professional and ethical responsibility, consequences of technology, use of machines, and social consciousness, declined between their freshman and senior year [5]. Her work surmised one of the ideological pillars of this culture is technical/social dualism. This dearth of engagement is bred when engineering students often view ethics as peripheral to engineering practice although in reality, the two are inextricably linked [6]. 
The very structure of engineering education contributes to students' sentiments towards ethics. The narrow technical emphasis of the engineering curriculum creates "a massive black hole whose gravitational pull inexorably absorbs the students' attention, time, and fidelity“ $[4$, p. 349]. The crowded curriculum also poses a challenge for programs interested in providing standalone ethics and societal impact (ESI) courses [6].

Beyond the barriers at the student and curricular level, many engineering faculty are ill prepared or unwilling to teach ethics. Without the educational background or incentives to acquire that knowledge within the academic reward system, "the average faculty member may not do a stellar job" integrating ESI into their classroom [4, pp. 348-49]. Herkert claims, "the greatest challenges, however, will confront engineering faculty" [7, p. 311]. When programs do not require or even offer a dedicated ethics course, "it is incumbent upon the engineering community" to integrate ethics "within the context of technical courses", "which begins with self-education" and "faculty development" [7, p. 311]. Haws expresses that for many engineers, "engineering ethics, at least the theoretical aspects of engineering ethics, is beyond our expertise" [8, p. 227]. However, Bucciarelli expresses that not feeling qualified does not negate the need for teaching it [9]. For ethics to be effectively integrated and prioritized in the curriculum, faculty engagement is essential [10].

A fundamental challenge in engineering education is the narrow conceptualization of ethics and the role of engineers. Ethics are framed by professional codes of ethics [10] but this paradigm has limitations. The individualistic approach of teaching ethics through cases of professional practice that emphasize the role of individual engineers and codes is a simplistic framing that averts attention from the broader context [11]. Engineers are not individualistic and autonomous in their work; instead, they "exist and operate as a node in a complex network" [12, p. 181]. Focusing on the individual actions and responsibilities of engineers often comes at the expense of examining the societal context, which confines ethics education [13-15]. This problem can be extrapolated to industry. The division of labor in engineering has brought a dilution of responsibility [16]. By only working on a small part instead of thinking of the whole, engineers are disconnected from their responsibility [12]. Instead, engineers need an awareness of holistic thinking to understand the unintended consequences of their products and designs and that paradigm shift needs to begin in the classroom [10]. ESI education must span both microethics, the decisions and responsibilities of individual engineers, and macroethics, the responsibilities of the profession to society, such as sustainability and social justice $[7,17]$. Furthermore, engineering education needs to engage ethical and societal issues instead of "engineer-izing" them [4]. Engineer-ization attempts to fit a square peg into a round hole by imposing technical problem solving on issues that are not meant to be solved that way. Conlon and Zandvoort also recognize the limitations of imposing technical problem-solving and assessment strategies because it assumes that ethical issues can be resolved with objectively correct solutions [11].

With an ever-increasing dependence on technology and globalization, the importance of educating engineering and computing students about ESI will only grow. Looking to the future, Zandvoort et al. argue one challenge will be integrating ethics in all programs and reaching all engineering students [15]. However, achieving this end will require overcoming "resistance from students, scientific educators, school directors and from the profession 
itself or sometimes from employers" [15, p. 300]. In the United States, $80 \%$ of engineering students graduate from programs that do not require an ethics course [7]. Although challenges in engineering ethics education have been well documented, the literature mainly comes from the observational and anecdotal perspective of few educators. This research attempts to better synthesize and characterize the challenges that faculty have encountered and how they have overcome them so that lessons can be extracted from their experience about how to effectively teach ESI to engineering and computing students. The following research questions are related to those objectives.

\section{Research Questions}

RQ1: What challenges have educators encountered or perceived when teaching engineering and computing students about ethics and the societal impacts of engineering and technology?

RQ2: For educators who did not face any challenges, what circumstances or strategies allowed them to effectively integrate ethics and societal impacts of engineering and technology into their courses, programs, and/or co-curricular activities?

\section{Methods}

\section{Data Collection}

The research presented in this paper is situated within a larger study with broad goals related to exploring the ESI education of engineering and computing students. The first phase of the study involved the development and dissemination of online surveys to understand how educators teach engineering and computing students about ESI. Survey participation was solicited via email from authors of papers on engineering ethics, National Science Foundation (NSF) grantees studying engineering ethics education, members of various American Society for Engineering Education (ASEE) divisions, and mentors of cocurricular engineering organizations. Additional information of the survey invitation and distribution has been published $[18,19]$. The survey questions probed at ethics related topics, teaching methods, and assessment strategies as well as instructional settings such as different course types and co-curricular activities. The survey also sought feedback on perceptions of the sufficiency of ESI education and broad perspectives regarding ESI. At the end of the survey, respondents were asked to provide their email address if they were willing to be contacted for a follow-up interview. Of the 1448 survey respondents, 230 indicated willingness to participate in an interview.

The second phase of the study involved conducting interviews with educators to learn more about their ESI instructional practices and general perspectives regarding the integration of ESI into the engineering curriculum and educational experiences of engineering students. Between September 2016 and April 2017, 52 survey respondents were contacted for interviews with the intention of conducting 36 interviews. Selection of these individuals was based on an iterative and collaborative process within the five-member research team. Broadly, we hoped to interview educators who taught a range of ethics-related topics using a variety of pedagogical and assessment strategies in different disciplinary and instructional settings. For the first wave of interview invitations, all five members of the research team were invited to review the survey responses and choose four or five individuals that they 
were interested in interviewing. During a team Skype meeting, everyone proposed their suggestions, generating a list of 19 names that were then contacted. After 16 interviews were conducted in the first wave, the process was repeated and the research team reached consensus on 15 more names. After this second solicitation, 10 more interviews were completed. The selection process and discussion was repeated for a third and final time, generating 18 names and leading to 11 interviews. Each member of the research team had different criteria but all were motivated to select educators who were thought to represent high impact ESI instructional practices. The primary criteria and rationale motivating the selections of each member of the research team are summarized in Table 1.

Table 1. Motivations for selecting educators to participate in interviews

\begin{tabular}{|l|l|}
\hline $\begin{array}{l}\text { Member of } \\
\text { Research Team }\end{array}$ & $\begin{array}{l}\text { Selection Rationale } \\
\text { sotaled the number of topics and teaching methods indicated in the } \\
\text { breadth, examined the responses to "Please share your thoughts about } \\
\text { the education of engineering and computing students regarding } \\
\text { broader impacts and ethical issues" for interesting perspectives, sought } \\
\text { out a range of disciplines and course types. }\end{array}$ \\
\hline 2 & $\begin{array}{l}\text { Selected individuals who reported teaching a large number of different } \\
\text { ethics topics in a large number of different course types and/or also } \\
\text { with co-curricular mentoring; with use of student-centered teaching } \\
\text { methods and strong assessment, looked for interesting write-in } \\
\text { comments. }\end{array}$ \\
\hline 3 & $\begin{array}{l}\text { Interested in selecting individuals who are well established in } \\
\text { engineering education research and who integrate ESI into co- } \\
\text { curricular activities. }\end{array}$ \\
\hline 4 & $\begin{array}{l}\text { Given that all potential candidates had significant credentials in } \\
\text { teaching engineering ethics, priority was placed on finding individuals } \\
\text { who were well versed in engineering education research, either in } \\
\text { conducting research or in applying research results to their own } \\
\text { teaching. It was hoped that such a group would provide a strong basis } \\
\text { for their pedagogical approach to teaching ESI. }\end{array}$ \\
\hline 5 & $\begin{array}{l}\text { Selected a balance of individuals who taught ESI in standalone } \\
\text { courses and who integrated ESI into technical engineering courses } \\
\text { with a representation of secular and religiously affiliated institutions. }\end{array}$ \\
\hline
\end{tabular}

All of the interviews were conducted over Skype or phone by the first author and lasted 3070 minutes. The interviews were audio recorded using Callnote. The semi-structured interviewees all followed the same script. The interviewees were asked to describe the setting they think was most effective in facilitating ethical development, the pedagogical approaches they used, the reasons they believe the approach is effective, and their motivation in teaching ESI in the particular setting. Questions also probed perceptions of student interest, challenges encountered in incorporating ESI, transferability of the course/activity content and structure, and institutional culture surrounding ESI education. Interviewees who have worked in industry, were educated outside of the United States, or 
teach outside of the United States were also asked how those experiences impacted their teaching. Following the interviews, the interviewer wrote two-page summaries including a description of ESI course/program/activity, why the instructor believed it to be effective in educating students, why the instructor perceived their ESI instructional approach as transferrable, and institutional support. Each summary was emailed to the participant for a member check to increase the accuracy and validity of the qualitative research [20]. After the summary was approved, a pseudonym was assigned to the participants using a random name generator to protect their confidentiality [21].

\section{Participants}

The demographic data is shown in Table 2 for both the complete group of interviewees and the sub-set included in this analysis on challenges. The participants represented mechanical, industrial, environmental, chemical, civil, biomedical, electrical, computer, and nuclear engineering. Several of the interviewees also had backgrounds and taught courses outside of engineering, such as liberal arts, applied ethics, philosophy, and psychology.

Table 2. Characteristics of educators who participated in interviews

\begin{tabular}{|lcc|}
\hline Demographic & $\begin{array}{l}\text { Interview Participants } \\
(\mathrm{n}=37)\end{array}$ & $\begin{array}{l}\text { Sub-set Included in } \\
\text { Analysis }(\mathrm{n}=31)\end{array}$ \\
\hline Gender & 25 & 20 \\
Male & 12 & 11 \\
Female & & 12 \\
\hline Academic Rank & 16 & 6 \\
Full professor & 7 & 9 \\
Associate professor & 10 & 2 \\
Assistant professor & 2 & \\
Senior instructor or other full-time non- & & 2 \\
tenure track & 2 & 20 \\
Departmental/college staff member & & 7 \\
Degrees & 26 & 4 \\
Engineering & 7 & 24 \\
Non-engineering & 4 & 4 \\
Both & & 3 \\
\hline Department Appointments & 30 & \\
Engineering & 4 & 1 \\
Non-engineering & 3 & 4 \\
Both & & 14 \\
Institution Type* & 1 & 2 \\
1B & 4 & 2 \\
1M & 18 & 0 \\
1D & 2 & 2 \\
2B & 2 & 2 \\
2M & 1 & \\
2D & 2 & \\
3B & 3 & \\
3M & & \\
& & \\
\hline
\end{tabular}


\begin{tabular}{|lll|}
$3 \mathrm{D}$ & 2 & 2 \\
International & 2 & 2 \\
\hline
\end{tabular}

*1: public, 2: private secular, 3: private religious, B: Bachelor's, M: Master's, D: Doctoral

At the beginning of the interview, participants were asked to describe the course they taught or co-curricular activity they mentor that they believe is the most effective in facilitating ethical development in their students. The participants were welcome to discuss one of the courses they mentioned on the survey or a different setting. Some individuals were not actively teaching, and described former courses that they had taught. The types of courses/programs/ activities described are shown in Table 3 (some educators described more than one).

Table 3. ESI Educational Settings Discussed in the 37 Interviews

\begin{tabular}{|l|c|}
\hline ESI Educational Setting & Count \\
\hline First-year introductory engineering course & 5 \\
Service-focused programs/courses/co-curricular activities & 6 \\
Required engineering courses & 4 \\
Elective engineering courses & 4 \\
Ethics/societal impacts-focused programs and courses & 13 \\
Professional issues focused courses & 4 \\
Capstone design courses & 4 \\
Graduate-level courses & 5 \\
\hline
\end{tabular}

\section{Data Analysis}

Content logs were created for each of the interviews [22]. The content logs included all of the interviewer questions and the general scope of the response with time stamps to more readily find information within the interview audio files. After all of the content logs were generated, the sections in which interviewees discussed challenges were noted. These sections were transcribed verbatim. In total, there were 114 segments across 31 interviews relevant to challenges (or lack there of) either in response to an explicit question about challenges or arising spontaneously in the conversation. Recording errors prevented two interviews from being transcribed and the remaining four did not discuss the presence or absence of challenges due to the semi-structured nature of the interviews and time constraints. The interview segments were analyzed using emergent, thematic coding [23]. After the first author coded all of the segments, the second author coded a random sub-set of 50 for inter-rater reliability. Agreement was tested in SPSS 24 using Cohen's kappa with almost perfect agreement inferred at values between 0.81 and 1.0, substantial agreement between 0.61 and 0.80 , and moderate agreement between 0.41 and 0.60 [24]. Only the codes with at least moderate agreement are discussed.

\section{Results and Discussion}

RQ1: Challenges Teaching ESI in Engineering/Computing

The codes were organized into five broad themes that represent the challenges that educators have perceived or encountered: (1) students (2) faculty (3) institution (4) curriculum (5) engineering skills. 


\section{Students}

Challenges related to students included disinterest, resistance, and difficulty learning about ESI. The sub-codes, definitions, frequencies (counts within the total number of segments), percentages of participants who mentioned the sub-code, and kappa values are displayed in Table 4.

Table 4. Challenges Themes Related to Students

\begin{tabular}{|llccc|}
\hline \multicolumn{1}{|c}{ Sub-code } & \multicolumn{1}{c}{ Definition } & $\begin{array}{c}\text { Frequency } \\
\text { (n of 114 } \\
\text { segments) }\end{array}$ & $\begin{array}{c}\text { Frequency } \\
\text { (\% of 31 } \\
\text { participants) }\end{array}$ & Kappa \\
\hline $\begin{array}{l}\text { Lack Student } \\
\text { Interest }\end{array}$ & $\begin{array}{l}\text { When students express a lack } \\
\text { of interest in learning about } \\
\text { ESI }\end{array}$ & 15 & 42 & 0.90 \\
$\begin{array}{l}\text { Student } \\
\text { Resistance }\end{array}$ & $\begin{array}{l}\text { When students express } \\
\text { resistance or do not } \\
\text { understand the purpose of } \\
\text { learning about ESI or } \\
\text { educators perceive their } \\
\text { pushback } \\
\text { When it is noted that ESI is } \\
\text { difficult for students to learn }\end{array}$ & 15 & 35 & 0.77 \\
Difficult & & 7 & 23 & 1.00 \\
\hline
\end{tabular}

\section{Lack of interest}

A lack of student interest in the classroom is problematic since interest and motivation are so closely connected, and important elements for learning [25]. When students are not engaged in the material, there are challenges for both teaching and learning. One interviewee who teaches ethics in a required professionalism seminar integrated with design noted that interest is "bimodal" with an even split between students who are and who are not engaged. Another interviewee who was responsible for teaching the Fundamentals of Engineering exam review for his program commented that the ethics session was always the least attended because "the idea was either that it's not important or who cares or this is all obvious stuff and I don't need to think about it." These comments show the challenge of teaching ESI when students are not interested in learning about it and/or they do not appreciate its value.

\section{Resistance}

Interviewees also discussed challenges they encountered when students explicitly expressed resistance or pushback to learning about ESI. One professor who teaches a required onecredit professionalism course in industrial engineering mentioned "anything that's not a formula or calculation, there are a few students who just think when we stray away from that, we're somehow harming their potential career as an engineer." Another professor who taught ESI in both elective standalone ESI and core engineering courses encountered similar resistance from students, which stemmed from their "anxiety about grades" and career preparation. In thermodynamics, students would remark “...'well you're taking away time I should be using to learn $x$ content of the class'... they get this sense that if you're taking time away from that, they get upset." A professor who taught capstone design in electrical 
and computer engineering experienced similar pushback from students who found teaching ESI in that course:

becomes very problematic not to see it as a bolt-on for the course and then you're taking time away from something valuable you could be doing, something the students are going to ding you on when it comes to evaluation time.

Students' perception that ESI content comes at the expense of more valued technical content can create a wall of resistance that not only impinges their motivation to learn but also instructors' ability to teach since the instruction is rendered less effective and they can become discouraged after receiving negative course evaluations.

\section{Difficulty}

Participants also mentioned the inherent challenges of teaching the theory and nuance of ethical and social issues to engineering and computing students. An interviewee who teaches a Science, Technology, and Society (STS) course required for all engineering students at an institution in Turkey explained,

in the early years, as a result of youthful inexperience on my part, I used more ambitious texts, including historical, sociological and cultural studies type texts. I realized in a few years that while the subject matter might be interesting for the students, they had difficulty parsing these texts. As engineering students, they had little experience reading extended texts with no equations or graphs and this discouraged them.

For many engineering students, ESI is unfamiliar territory that requires a different way of thinking. This challenge is congruent with Haws' explanation that "the problem is that engineering attracts convergent thinkers who tend to become oblivious to the wider ramifications of their work... ethical behavior requires divergent thinking - considering options and impacts beyond the narrow realm of engineering" [8, p. 223].

\section{Faculty}

Interviewees discussed the challenges they encountered from other faculty members in terms of a lack of interest, lack of training or experience related to ESI, and need for development, as shown in Table 5. 
Table 5. Interview themes related to challenges associated with faculty

\begin{tabular}{|c|c|c|c|c|}
\hline Sub-code & Definition & $\begin{array}{l}\text { Frequency } \\
\text { (n of } 114 \\
\text { segments) }\end{array}$ & $\begin{array}{c}\text { Frequency } \\
\text { (\% of } 31 \\
\text { participants) }\end{array}$ & Kappa \\
\hline $\begin{array}{l}\text { Lack Faculty } \\
\text { Interest/ } \\
\text { Support }\end{array}$ & $\begin{array}{l}\text { When lack of support or } \\
\text { interest from the faculty or } \\
\text { department for teaching ESI is } \\
\text { mentioned }\end{array}$ & 24 & 48 & 0.43 \\
\hline $\begin{array}{l}\text { Lack Faculty } \\
\text { Training/ } \\
\text { Experience }\end{array}$ & $\begin{array}{l}\text { When the lack of engineer } \\
\text { faculty's industry experience to } \\
\text { discuss ESI in the context of } \\
\text { their real-world work or the } \\
\text { ESI training to effectively } \\
\text { integrate these topics into their } \\
\text { classes is noted }\end{array}$ & 14 & 32 & 0.55 \\
\hline $\begin{array}{l}\text { Need for } \\
\text { Faculty } \\
\text { Development }\end{array}$ & $\begin{array}{l}\text { When it is noted that there is a } \\
\text { need for engineering faculty } \\
\text { development or training to } \\
\text { effectively teach ESI }\end{array}$ & 5 & 13 & 0.73 \\
\hline
\end{tabular}

Lack of interest and support

Some of the interviewees described challenges they encountered in terms of a lack of support and interest from their colleagues in teaching ESI to engineering and computing students. One participant noted, "way too many engineering faculty don't consider this important." Another commented,

the faculty generally believe that all engineering knowledge is technical, they seem not to understand that engineering ethics is part of the non-technical knowledge that engineers need to have... there's this feeling that if it's not technical, then it's not something we want to be teaching in the department.

The engineering professor who teaches STS for engineering students in Turkey remarked, "most faculty members are ignorant of and disinterested in what is going on in this course. A few may also view it with suspicion with regards to whether it serves any useful purpose." Another interviewee in a liberal arts and international studies department who teaches humanitarian engineering courses commented,

I would say, for most faculty it's [ethics education] completely invisible... They do not acknowledge the importance of ethics in their own classrooms. If you talk to them and say do you think ethics education is important for engineers, they'll say 'yeah, but just don't put it in my classroom.'

Whether faculty colleagues are disinterested in ESI or think it does not belong in engineering, their lack of support can isolate the educators who are teaching these topics while making it more challenging to cohesively integrate them across the curriculum. 
Lack of training/experience

Not all of the interviewees experienced antagonism from their colleagues but still noted that a lack of ethics training and/or industry experience were barriers to effectively integrating ESI into engineering courses. One interviewee who has a background outside of engineering and teaches ethics to computer science and biomedical engineering students noted,

the problem is that at least at my institution, this is an R1, most of these faculty have never been in industry so maybe the ethical issue they've faced is running a lab.... But by in large, most of them have no experience in industry to be able to talk about the kinds of things that most of our students are going to experience because they're going into industry so that's a problem from the get-go.

Without experience of their own, engineering educators can have difficulty contextualizing ethical and social concerns and not feel comfortable covering issues that students will encounter in practice. Furthermore, for many engineering educators, ethics was not part of their own education or background. One interviewee commented that engineering faculty members are "not really trained in the social sciences or liberal arts for the most part so they lack the kind of nuanced understanding of how to bring ethics into the classroom." Another professor who integrates ESI into a junior-level required undergraduate electrical engineering course noted,

I don't think I'm just projecting my own experience here, it's that we instructors don't really have a strong command of how this connects because it's bigger than one person's experience... It's a very rare individual who has a footing enough in the content that they're teaching and a footing enough in the social analysis that they can bring that into the undergraduate space.

Another interviewee expressed a similar challenge in "that many faculty don't feel qualified to teach ethics." Professional codes and rules of practice dictate that engineers should stay within their areas of competence, and without formal training in ethics let alone expertise in the matter, engineering educators can feel reluctant to teach ESI. An interviewee who integrates ESI into an elective graduate nuclear engineering course commented,

we [faculty] rarely actually discuss broader economic, social, and political issues, which is not limited to here... there is a reticence regarding these issues where we are kind of reluctant to branch out beyond the strictly technical to discuss these issues.

Need for faculty development

The lack of training and education fosters the need for faculty development. If engineering educators are more comfortable with ESI topics they might give greater consideration to teaching them into their courses. An interview explained,

I think for the majority of the faculty though, they still don't feel equipped so we're still trying to figure out how to help the typical faculty member understand this and recognize the issues related to that, so again, work on developing tools... not that it's 
hostile, I just think that most faculty don't feel equipped to address these issues in the majority of courses.

Faculty development can help bridge that gap and enable more educators to feel confident integrating ESI and engineering.

\section{Institution}

Some interview participants noted resistance on the institutional level, including a lack of support and promotion systems that do not recognize the value of ESI education, shown in Table 6.

Table 6. Interview themes associated with institutional challenges

\begin{tabular}{|c|c|c|c|c|}
\hline Sub-code & Definition & $\begin{array}{l}\text { Frequency } \\
\text { (n of } 114 \\
\text { segments) }\end{array}$ & $\begin{array}{c}\text { Frequency } \\
(\% \text { of } 31 \\
\text { participants) }\end{array}$ & Kappa \\
\hline $\begin{array}{l}\text { Lack } \\
\text { Institution } \\
\text { Support }\end{array}$ & $\begin{array}{l}\text { When the institution as a } \\
\text { whole is not supportive of ESI } \\
\text { instruction or teaching ESI is } \\
\text { noted as adverse to academic } \\
\text { career and is not rewarded } \\
\text { within the promotion/tenure } \\
\text { system }\end{array}$ & 10 & 29 & 0.62 \\
\hline
\end{tabular}

One interviewee who teaches civil engineering courses and is the faculty advisor for the student chapter of Engineers Without Borders (EWB) at a public doctoral: highest research activity university [26] discussed that although participating in EWB as a student and now as a mentor was valuable to his technical training and understanding of ESI, it was not rewarded at the institution. As a young, tenure track faculty, the participant said,

I basically get a pat on the back for my involvement with EWB. They like it, but it's not going to get me tenure, publications and proposals are getting me tenure so you have to sacrifice some of that... if you talk to old tenure faculty, they'd probably say that's career suicide, don't spend a month of your time in service work if you're not getting any benefit from it.

Although this work is not recognized or rewarded formally in the tenure system, it serves as an imperative opportunity to teach students about ESI in the context of projects for developing communities. The interviewee explained that EWB "is the only thing that I think I do well here as far as teaching ethics in engineering."

Another interviewee noted that engineering professors can feel reluctant to teach ESI when students express disinterest and resistance, which is manifested in lower course evaluations. She conceded, "you obviously can't completely tank your teaching evaluations, [but] I think we faculty live in fear of consequences that don't materialize in reality." The impetus is thus on the institution to either recognize the value of teaching students about ESI regardless of 
students' potentially adverse reactions or reduce educators' anxiety about the perceived ramifications.

\section{Curriculum}

Interview participants cited a number of curricular challenges to teaching ESI, summarized in Table 7.

Table 7. Interview themes associated with challenges related to curriculum

\begin{tabular}{|c|c|c|c|c|}
\hline Sub-code & Definition & $\begin{array}{l}\text { Frequency } \\
\text { (n of } 114 \\
\text { segments) }\end{array}$ & $\begin{array}{c}\text { Frequency } \\
(\% \text { of } 31 \\
\text { participants })\end{array}$ & Kappa \\
\hline Accreditation & $\begin{array}{l}\text { When ABET is noted or } \\
\text { ESI are treated just as an } \\
\text { accreditation } \\
\text { requirement to fulfill }\end{array}$ & 16 & 39 & 0.62 \\
\hline $\begin{array}{l}\text { Packed } \\
\text { Curriculum }\end{array}$ & $\begin{array}{l}\text { When the engineering } \\
\text { curriculum is already } \\
\text { crowded with technical } \\
\text { content and there is } \\
\text { limited curricular space } \\
\text { for ESI }\end{array}$ & 14 & 29 & 0.43 \\
\hline $\begin{array}{l}\text { Required vs. } \\
\text { Elective }\end{array}$ & $\begin{array}{l}\text { When the challenges } \\
\text { associated with teaching } \\
\text { ESI in required versus } \\
\text { elective courses are } \\
\text { noted }\end{array}$ & 7 & 19 & 0.56 \\
\hline
\end{tabular}

\section{Accreditation}

Although ABET is a motivator for the inclusion of ethical responsibilities and societal contexts, some educators perceive accreditation to be a barrier to effective ESI instruction. An interviewee noted, "by ABET standards we are required to do engineering ethics...we are nominally ticking that box... but more confined to safety culture and intellectual integrity." When programs treat ethical responsibility merely as a requirement to fulfill, there is a disservice to the content. Another interviewee commented,

...of course it's required by ABET and that's always you know the reason you have to do it... but faculty are antagonistic toward ABET because they think it impinges upon their academic freedom and so it's really hard to get people to do ethics just because ABET requires it.

According to some participants, accreditation can reduce ESI instruction to a matter of compliance.

$\underline{\text { Packed Curriculum }}$

Another commonly cited curricular challenge is the limited space to teach ESI. Even with the best intentions, programs can struggle to effectively integrate ESI with a curriculum that 
is already overstuffed with technical content. A civil engineering professor who is part of a program that is introducing an ethical thread explained that,

the problem that we've found with that is how to do it, how to weave that into our courses without taking out content that already exists in our courses to put something else in there. So that's been a challenge I think, trying to just find space to fit it in without taking away what we're already doing.

Technical demands in the curriculum leave few opportunities to teach ethics directly in core engineering courses. Additionally, there is limited opportunity to include a standalone ESI course. Another interviewee explained that the program:

can't do full engineering ethics course because the state has told us that we can only do 120 credits over 4 years and right now most of our majors are at 132, 136, they are trying to figure out how to cut 3 or 4 required classes from the engineering major right now so they're not going to go add a whole class on engineering ethics... a lot of us are in this packed curriculum place where there are well meaning people who can't get access to the students on ethics.

One of the challenges inherent in the engineering curriculum is that it privileges technical content, and when that material is devoid of ethical considerations and societal impacts, these topics can be treated as separate but not equal. An interviewee who is involved with a macroethics education program described the motivation behind integrating these topics throughout the curriculum.

We see technical social dualism as a barrier to rendering visible broader social impacts both in and around the curriculum. And technical social dualism just means that you make a mental split between the technical and the social. And you put one over here, and the other over here... So, I'd say that that sense of that - that technical social dualism is reinforced throughout the curriculum, but especially in the - in two large areas of the curriculum in engineering science courses and humanities and social science courses. So, while the technical engineering science courses focus and - and privilege the technical, the humanities and social science courses in many universities do just the opposite.

The separation of technical and social within the curriculum reinforces the perceived separation in students' minds, which is not reflective of engineering practice where the two have to be considered simultaneously.

\section{Requirements vs. elective}

Some interviewees also commented on the challenges associated with teaching ESI in required versus elective courses. Elective courses are conducive to high engagement and motivation because student self-select into them based on prior interest. An interviewee who has taught ethics in elective standalone courses and required core engineering courses noted, 
the difference between doing that class as an elective where everybody that took that class wanted to be there, whereas if I did something like that in my thermodynamics class, yeah there would be students who say 'why are we doing this, this is ridiculous, this doesn't belong in a thermodynamics class.'

Required and elective courses have distinct limitations and affordances in terms of teaching ESI which need to be taken into account when designing curricular approaches.

\section{Engineering Skills}

Broad perceptions of ethical and social skills at the topical level were also cited as challenges, as displayed in Table 8. The distinction between hard and soft, or technical and non-technical skills, and the notion that ESI do not fall in the realm of real engineering were described as fundamental barriers to teaching these topics.

Table 8. Interview themes associated with challenges due to engineering skills

\begin{tabular}{|llccc|}
\hline \multicolumn{1}{|c}{ Sub-code } & \multicolumn{1}{c}{ Definition } & $\begin{array}{c}\text { Frequency (n of } \\
\text { 114 segments) }\end{array}$ & $\begin{array}{c}\text { Frequency } \\
\text { (\% of 31 } \\
\text { participants) }\end{array}$ & Kappa \\
\hline $\begin{array}{l}\text { Hard/Soft } \\
\text { Skills }\end{array}$ & $\begin{array}{l}\text { When the delineation } \\
\text { between hard and soft or } \\
\text { technical and non- } \\
\text { technical skills at the topic } \\
\text { level is mentioned }\end{array}$ & 9 & 26 & 0.63 \\
Not & $\begin{array}{l}\text { When ESI are considered } \\
\text { Engineering } \\
\text { outside the definition } \\
\text { ef/not relevant to } \\
\text { engineering by students, } \\
\text { faculty, or institution }\end{array}$ & 14 & 26 & 0.55 \\
\hline
\end{tabular}

Hard/soft skills

ABET EC2000 formalized the distinction between hard skills (criterion 3 student outcomes $\mathrm{a}, \mathrm{b}, \mathrm{c}, \mathrm{d}$, and $\mathrm{k}$ ) and professional skills (outcomes d, f, g, h, i, and j) [27]. The new ABET criteria reaffirm this separation with outcomes 1,2 , and 3 covering technical skills and 4,5 , 6, and 7 relating to professional skills [1]. Since at least 1994, ASEE has referred to this second group as professional skills, "although certain engineering educators refer to these as 'soft' skills, often in naïve and occasionally derogatory fashion" [28, p. 41]. In its Body of Knowledge, the National Society of Professional Engineers organizes 30 capabilities into basic or foundation, technical, and professional practice [29]. However, this distinction remains as a challenge for some of the interview participants who were confronted with the implication that ethical responsibilities and societal impacts were "soft". An interviewee who teaches a course in which students are involved with a design project for a developing community explained,

I automatically react to anyone referring to recognizing the relationship between engineering and human kind as a soft skill because to me that's the most technical skill, to be able to know what's right to do when. 
Another interviewee echoed a similar sentiment with "people talking about the professional skills, the hard skills and soft skills... we call them professional skills... I think in reality, those skills are much harder to learn." Both of these educators found that calling ethical and societal skills "soft" is a disservice to their complexity since these skills can be the most challenging to teach and learn. Another interviewee expressed that even calling these skills professional does not do them justice since they are inextricably part of the engineering.

People used to call them soft skills... then people started calling them professional skills, but I think we need to call them engineering skills because they're all engineering skills... every time we do that separation, the technical and social, we're creating this false separation and we keep reinforcing it in different ways.

Not engineering

A related challenge is the marginalization of ESI and its treatment as not real engineering. The exclusion of ESI from the technical engineering curriculum gives students the impression that ethical and societal responsibilities are not an inherent part of engineering. An interviewee who teaches in electrical engineering noted, "every time we try to teach ethics, it's seen as an add-on, a bolt-on to the program, it's outside students' purview of what engineering should be." As a result, the department for which he is the chair changed their approach to ethics education by integrating it into capstone design in the context of the student projects instead of teaching it through isolated modules. Another educator experienced similar pushback and stated, "once in a while, a student will raise kind of an objection on principle that this is not engineering, 'I'm in engineering, this is not engineering stuff that we're doing"'. This perception is not unique to students, another interviewee explained as the only educator in the department integrating ESI into engineering classes, "it ends up being stigmatized... the person that ends up doing it, at least in my case, ends up getting labeled not a real engineer." To shift the paradigm ESI "has to be applied by every last engineering professor that they [students] see... they get this idea that 'real engineers' don't think about ethics." To overcome this challenge, all engineering educators should share the responsibility of teaching ESI. This more cohesive approach will demonstrate the importance of ESI without isolating the few educators in each department who teach those topics.

\section{RQ2: Not Barriers or Challenges}

Not all of the educators faced or perceived challenges in teaching engineering and computing students about ESI and 64\% described their experiences with both challenges in some areas and lack of challenges in others. Their experiences shed light on the circumstances and strategies that are conducive to ESI education in their varying contexts. The theme of lack of challenges was threaded across the student, faculty, and institution levels. 
Table 9. Lack of challenges related to particular areas noted by interviewees

\begin{tabular}{|llccc|}
\hline \multicolumn{1}{|c}{ Sub-code } & \multicolumn{1}{c}{ Definition } & $\begin{array}{c}\text { Frequency } \\
\text { (n of 114 } \\
\text { segments) }\end{array}$ & $\begin{array}{c}\text { Frequency } \\
\text { (\% of 31 } \\
\text { participants) }\end{array}$ & Kappa \\
\hline $\begin{array}{l}\text { Student } \\
\text { Interest }\end{array}$ & $\begin{array}{l}\text { When student interest and } \\
\text { engagement in ESI is noted }\end{array}$ & 22 & 58 & 0.62 \\
$\begin{array}{l}\text { Faculty } \\
\text { Support }\end{array}$ & $\begin{array}{l}\text { When support for teaching ESI } \\
\text { from the faculty and/or } \\
\text { department is mentioned }\end{array}$ & 17 & 48 & 0.81 \\
$\begin{array}{l}\text { Institutional } \\
\text { Support }\end{array}$ & $\begin{array}{l}\text { When support is noted for ESI } \\
\text { at the institutional level }\end{array}$ & 10 & 23 & 0.88 \\
\hline
\end{tabular}

Student interest

Among the 31 interviewees, 58\% found students to be interested in learning about ESI. This sub-code could be mentioned by itself or embedded in a comment that also included lack of interest or resistance to show students' differential response to ESI in different settings or with various approaches. For example, a psychology professor with a dual appointment in computer science explained how he changed a required ethical issues in software design course and its impact on student interest.

When I used to teach this as an ethical issues course, there were students who were blasé about it, they just wanted the cool parts about hackers. I have not had a student be bothered by this since, all of them realize they have a real client who is looking to them for advice on these ethical issues. Oddly enough, after they participate in this, they no longer ask they question 'are there ethical issues associated with the design of software', because they've spent the whole semester convincing someone else that there are.

In his experience, students were initially uninterested in ethical issues. However, when he restructured the course so that it was focused on projects in which student teams spent the semester working for a real client to understand and explain the ethical issues embedded in their software, their engagement grew as they could connect to the relevance of ESI. Teaching about the ethical and societal implications of engineering can also tap into students' motivation to do something meaningful. One interviewee noted,

I think most students that I have want to do something that matters, they don't want to just play games, they don't want to feel like they're a cog in the machine... I think they really like knowing that what they do matters and some of the stuff that you talk about really is very topical.

By incorporating current events and news stories into the classroom, the interviewee found students to be very engaged in the material. In the dynamic systems class, she discussed autonomous vehicles and considered both the technology and its impact in a personalized way. A philosophy professor who teaches an ethics course focused on modern engineering and science controversies said, 
I have found over and over again at both undergraduate and graduate levels, when you sit down with engineers and help them unpack dense ideas, ethical ideas, they are hungry for the conversation.

\section{Faculty support}

Other participants explained that they did not encounter challenges on the faculty level because their department created an environment that was welcoming of ESI instruction, This code was almost exclusively associated with interviewees at Bachelor's and Master's institutions and was more prevalent for religiously affiliated universities. One interviewee who teaches at a private Master's university with six professors in the department noted, "we have a relative few number of faculty, they're all strongly supporting it... when you have a smaller group, it is easier to get consensus." Another at a public Master's university said the integration of ESI across the curriculum was cohesive and that "I am really lucky to be in a small, new, novel program where I really only have one or two other people that I need to convince". For another interviewee at a private Master's university, the religious affiliation of the institution enabled support and consensus across the engineering programs.

Our faculty very much champion our student thinking through who they are in their faith, that's really kind of our big picture of how we view ethics... that's so integrated with all the worldview of every person in the department so in that sense there's not really pushback.

The professor of psychology who teaches software ethics at a religiously affiliated Bachelor's institution found that by working with the computer science department to teach ethics across the curriculum, the program has fostered high faculty support while creating an appealing curriculum for students.

I think from the beginning of the course, and I started teaching it in the 1990s, it has been welcomed by the faculty... it has been used as a recruiting tool when they talk to students about what makes their program different from a variety of other programs. So I think we've got pretty much complete faculty buy-in... it's really well integrated into the program.

\section{Institutional support}

Top-down support from the institution can also enable a strong culture for teaching ESI. The administration sets the tone for the university with a trickle down effect that can enhance or impinge ESI education. An interviewee who teaches graduate ethics courses for biomedical and software engineering students at a private religiously affiliated Master's university explained that the required courses were well supported.

The university as a whole really, really emphasizes ethics education so that is terrific, they're trying to get ethics across the curriculum, ethics into everything so that is something the university is really good at... they work really hard emphasizing ethics over and over again on campus as much as it's feasible. 
When asked about any challenges she faced in teaching ESI to chemical and paper science engineering students at a public Master's institution, one interviewee responded,

that's a really interesting question, well no. But it's interesting that you would ask that because it indicates that does happen at other institutions, which is a matter of concern not for me, because it's not my problem... it's really disappointing to think that there are engineering programs out there that are not convinced that teaching ethics and safety and professional behavior are an important part of engineering education, that's sad.

\section{Limitations}

Although in-depth interviews are valuable for the level of detail they generate, there are limitations in terms of generalizability [30]. Participants were selected to represent a range of institutions, settings, and disciplines along with a variety of topics, pedagogies, and assessment strategies; however, the sample was limited to those who were willing to participate. The language of the survey invitation and consent made the ESI focus of the study explicit, thus those who do not teach ESI might not have participated. As a result, the survey respondents are presumably not representative of the engineering community at large. The interview pool was further limited to those who were interested in taking the time to be interviewed. These educators could be more interested in ESI education and have more experience teaching it. There are likely other engineering educators who have considered or tried teaching ESI and experienced other challenges.

\section{Summary and Conclusions}

This study examined the experiences of 31 educators teaching engineering and computing students about ESI. Interviewees described the settings in which they integrate ESI, their pedagogical approaches, and their perceptions of student interest and impact. The educators also reflected on any challenges they encountered in incorporating these topics into their courses and co-curricular activities. Coding of the interviews revealed that participants faced challenges related to students, faculty, institution, curriculum, and engineering skills.

On the student level, $42 \%$ of the interviewees encountered lack of interest, $35 \%$ experienced resistance, and 23\% noted that ESI is difficult to learn. Related to other faculty, $48 \%$ of the interviewees perceived a lack of interest and support from their colleagues, $32 \%$ described a lack of training or experience needed to teach ESI, and 13\% noted faculty development is needed in this area. Institutionally, $29 \%$ of the interviewees mentioned a lack of support as a barrier to effective ESI education. These results indicate the need to foster an understanding of the importance of ESI and a community for its support across all levels. Finding and developing faculty allies will create a more conducive environment for ESI instruction while enabling more opportunities for its integration across the curriculum.

On the curricular level, 39\% of the interviewees perceived accreditation as a challenge, $29 \%$ described the limited space available in the curriculum to teach ESI, and 19\% compared the challenges of teaching in required versus elective courses. Although ABET requires the inclusion of ethical responsibility and societal context and is often cited as a motivator for the design and implementation of ESI content [3], it can be a barrier to effective instruction 
when treated as a box to check. The challenges of limited curricular space mentioned in the interviews is congruent with barriers noted in the literature [4]. However, there are strategies for teaching ESI without relying on the development of a dedicated course or pushing out technical content. Micro-insertions provide contextualized opportunities to briefly discuss ESI in technical courses [31]. One interviewee mentioned the Dakota Access Pipeline in a fluids class to bring relevant social context to a pipe calculation; another discussed the VW emission scandal in thermodynamics. These brief connections can have a cumulative effect for students by increasing their awareness of ESI and how it relates to engineering outside of the classroom.

Interviewees also commented on how the defined scope of engineering skills is a barrier with $26 \%$ discussing the delineation between hard and soft skills and $26 \%$ describing how ESI can be seen as outside of real engineering. Integrating ESI throughout the technical curriculum demonstrates its relevance to engineering, contextualizes it in material that students see as relevant to their careers, and supports its reinforcement like other engineering skills $[6,32]$.

In describing their teaching experiences, $64 \%$ of the interviewees noted both challenges and affordances and $13 \%$ encountered no significant challenges. Overall, $58 \%$ of the participants noted that students are interested in learning about ESI. When ESI is in context and connected to technical material, students understand the relevance, appreciate its inherent value in engineering, and see the ethical and societal implications of their work. Fear of a lack of emotional engagement from students should not prevent educators from integrating ESI, they just have to find ways to connect with students. On the faculty level, $48 \%$ of interviewees noted support from their colleagues. Having a supportive departmental environmental can provide a more cohesive approach to ESI education and be more inclusive of the educators who teach these topics. The interviewees who discussed support and interest from their colleagues were predominantly at Bachelor's and Master's institutions, suggesting these smaller, teaching-focused universities have a stronger ESI education culture than Doctoral, research-focused universities. Educators at religiously affiliated institutions also reported more support in their department.

Future work could probe educators' perceptions of challenges through the lens of diversity issues, such as whether experiencing particular barriers varied based on gender, academic rank, or professional background. Future work will also examine exemplars of ESI instruction chosen from the group of interviewees. This phase of the study will triangulate the perspectives of students (via pre and post surveys, interviews, and focus groups), faculty (via follow-up interviews), and alumni (via surveys and interviews) to understand highimpact teaching settings and strategies. This work will further explore challenges from different stakeholders, how those challenges were overcome, and what lessons can be extracted in the development of ESI education best practices.

\section{Acknowledgements}

This material is based on work supported by the National Science Foundation under Grant Nos.1540348, 1540341, and 1540308. Any opinions, findings, and conclusions or 
recommendations expressed in this material are those of the author(s) and do not necessarily reflect the views of the National Science Foundation.

\section{References}

[1] ABET, "Revisions to the Criteria for Accrediting Engineering Programs", Engineering Accreditation Commission, Baltimore, MD, 2017.

[2] NSPE, "Code of Ethics for Engineers", National Society of Professional Engineers, Alexandria, VA, 2017.

[3] J. Hess and G. Fore, "A Systematic Literature Review of US Engineering Ethics Interventions", Science and Engineering Ethics, 2017.

[4] B. Newberry, "The dilemma of ethics in engineering education", Science and Engineering Ethics, vol. 10, no. 2, pp. 343-351, 2004.

[5] E. Cech, "Culture of Disengagement in Engineering Education?," Science, Technology, \& Human Values, vol. 39, no. 1, pp. 42-72, 2013.

[6] J.A. Cruz and W.J. Frey, "An effective strategy for integrating ethics across the curriculum in engineering: An ABET 2000 challenge," Science and Engineering Ethics, vol. 9, no. 4, pp. 543-568, 2003.

[7] J. Herkert, "Engineering ethics education in the USA: Content, pedagogy and curriculum", European Journal of Engineering Education, vol. 25, no. 4, pp. 303-313, 2000.

[8] D. Haws, "Ethics Instruction in Engineering Education: A (Mini) Meta-Analysis", Journal of Engineering Education, vol. 90, no. 2, pp. 223-229, 2001.

[9] L. Bucciarelli, "Ethics and engineering education", European Journal of Engineering Education, vol. 33, no. 2, pp. 141-149, 2008.

[10] A. Colby and W. Sullivan, "Ethics Teaching in Undergraduate Engineering Education", Journal of Engineering Education, vol. 97, no. 3, pp. 327-338, 2008.

[11] E. Conlon and H. Zandvoort, "Broadening Ethics Teaching in Engineering: Beyond the Individualistic Approach", Science and Engineering Ethics, vol. 17, no. 2, pp. 217-232, 2010.

[12] J. Basart and M. Serra, "Engineering Ethics Beyond Engineers' Ethics", Science and Engineering Ethics, vol. 19, no. 1, pp. 179-187, 2011.

[13] J. Herkert, "Future directions in engineering ethics research: Microethics, macroethics and the role of professional societies", Science and Engineering Ethics, vol. 7, no. 3, pp. 403-414, 2001.

[14] R. Hudspith, "Broadening the Scope of Engineering Ethics: From Micro-Ethics to MacroEthics", Bulletin of Science, Technology \& Society, vol. 11, no. 4-5, pp. 208-211, 1991.

[15] H. Zandvoort, I. VanDePoel and M. Brumsen, "Ethics in the engineering curricula: Topics, trends and challenges for the future", European Journal of Engineering Education, vol. 25, no. 4, pp. 291$302,2000$.

[16] I. van de Poel, "Chapter 12", in Philosophy in Engineering, 1st ed., S. Christensen, M. Meganck and B. Delahousse, Ed. Aahrus: Authors and Academica, 2007, pp. 245-262.

[17] J. Herkert, "Ways of thinking about and teaching ethical problem solving: Microethics and macroethics in engineering", Science and Engineering Ethics, vol. 11, no. 3, pp. 373-385, 2005.

[18] A.R. Bielefeldt, N.E. Canney, C. Swan, and D. Knight. "Efficacy of Macroethics Education in Engineering". American Society for Engineering Education (ASEE) Annual Conference and Exposition. New Orleans, LA, June 26-28, 2016, 21 pp. DOI 10.18260/p.26919.

[19] D.W. Knight, N.E. Canney, A.R. Bielefeldt, and C. Swan. "Macroethics instruction in co-curricular settings: The development and results of a national survey". IEEE Frontiers in Education (FIE) Conference Proceedings, Erie, PA, Oct. 12-15, 2016.

[20] L.E. Koelsch,"Reconceptualizing the Member Check Interview." International Journal of Qualitative Methods, vol. 12, no. 1, 2013.

[21] L.M. Given, The Sage encyclopedia of qualitative research methods, Los Angeles, CA: Sage Publications, 2008. 
[22] J. Lofland, Analyzing social settings: a guide to qualitative observation and analysis. Belmont, Calif. [u.a.]: Wadsworth, 2009.

[23] J. W. Creswell, Qualitative Inquiry \& Research Design: Choosing Among Five Approaches, Thousand Oaks, CA: Sage Publications, 2007.

[24] J. Landis and G. Koch, "The Measurement of Observer Agreement for Categorical Data", Biometrics, vol. 33, no. 1, p. 159, 1977.

[25] L. Vanasupa, J. Stolk, and R.J. Herter, "The Four-Domain Development Diagram: A Guide for Holistic Design of Effective Learning Experiences for the Twenty-first Century Engineer", Journal of Engineering Education, vol. 98, no. 1, pp. 67-81, 2009.

[26] The Carnegie Classification of Institutions of Higher Education. Basic Classification Description. $\mathrm{http} / / /$ carnegieclassifications.iu.edu/classification_descriptions/basic.php

[27] ABET, "Criteria for Accrediting Engineering Programs", Engineering Accreditation Commission, Baltimore, MD, 2016.

[28] L. Shuman, M. Besterfield-Sacre and J. McGourty, "The ABET "Professional Skills"- Can They Be taught? Can They be Assessed?", Journal of Engineering Education, vol. 94, no. 1, pp.41-55, 2005.

[29] Licensure and Qualifications For Practice Committee, "Professional Engineering Body of Knowledge", National Society of Professional Engineers, 2013.

[30]C. Boyce and P. Neale, "Conducting In-depth Interviews: A Guide for Designing and Conducting In-Depth Interviews for Evaluation Input", Pathfinder International, Watertown, MA, 2006.

[31] M. Davis, "Integrating ethics into technical courses: micro-insertion", Science and Engineering Ethics, vol. 12, no.4, pp.717-730, 2006.

[32] $\mathrm{Li}$ and $\mathrm{S}$. Fu, "A Systematic Approach to Engineering Ethics Education", Science and Engineering

Ethics, vol. 18, no. 2, pp. 339-349, 2010. 